\title{
Proximal femoral resection and Tensor Fascia Lata flap for recalcitrant trochanteric pressure ulcers
}

\author{
Roop Singh ${ }^{1} \cdot$ Jitendra Wadhwani $\mathbb{D}^{1} \cdot$ Rajesh Kumar Rohilla ${ }^{1} \cdot$ Kiranpreet Kaur $^{2}$
}

Received: 12 June 2018 / Revised: 21 January 2019 / Accepted: 22 January 2019

(c) International Spinal Cord Society 2019

\begin{abstract}
Introduction Trochanteric pressure ulcers (PrUs) are difficult to treat and are often complicated by infection spreading to the hip joint. We review three cases from India where proximal femoral resection and pedicled Tensor Fascia Lata (TFL) flapping was used in the management of infected deep trochanteric ulcers communicating to the hip joint.

Case presentation Three patients had a total of four trochanteric PrUs communicating to the hip joint. Proximal femoral resection along with radical debridement of the pressure ulcer (PrU) was the first step in our surgical protocol. Serial debridements were performed to make the resulting cavity healthier and ready for the subsequent flap surgery. TFL flapping was done to cover the raw area of the PrU and the donor site was closed either primarily or with a split skin graft. All patients were males with AIS A spinal cord injury (SCI) and stage 4 PrUs in the trochanteric region. One patient had bilateral trochanteric ulcers. There was complete healing of all PrUs with improvement in wheelchair mobility, and general health. Discussion PrUs are a common complication of patients with SCI and are often considered one of the most neglected issues of health care delivery in India. Proximal femoral resection with pedicled TFL muscle flap is a versatile and reliable procedure for the coverage of recalcitrant trochanteric PrU with hip joint involvement. Minimal donor site morbidity occurs.
\end{abstract}

\section{Introduction}

Pressure ulcers (PrUs) are a common cause of morbidity after spinal cord injury (SCI). PrUs are often considered one of the most neglected issues of health care delivery in India, with a prevalence of PrUs in hospitalised patients ranging from 4.94 to $7.8 \%$ at different tertiary health care centres $[1,2]$. A comparison with other countries is presented in Table 1 [1-5]. Trochanteric ulcers often involve the deeper tissues and are followed by communication to hip joint leading to a refractory disease pattern. PrUs can be complicated by septic arthritis, persistent infection, persistent fever, recurrent ulceration, draining sinus, and multiple reconstruction failures [6]. Our study describes three patients where multiple debridements followed by

Roop Singh

drroopsingh@ rediffmail.com

1 Department of Orthopaedic Surgery, Paraplegia \& Rehabilitation, Pt. B.D. Sharma PGIMS, Rohtak-124001 Haryana, India

2 Department of Anaesthesiology and Critical Care, Pt. B.D. Sharma PGIMS, Rohtak-124001 Haryana, India proximal femoral resection and pedicled Tensor Fascia Lata (TFL) flap surgery based on the lateral circumflex femoral artery supply, was used in the management of deep trochanteric ulcers with infection communicating to the hip joint. This method provides adequate muscle bulk to fill the resultant cavities.

\section{Case presentations}

Three patients with a total of four trochanteric PrUs were included in the study. Demographics are presented in Table 2. All the ulcers were communicating to the ipsilateral hip joint. The surgical protocol contained three parts; the preoperative, the operative and the postoperative stage. In the preoperative stage a clinical examination of the PrU was performed to identify the communication with the ipsilateral hip joint. Tissue samples for bacterial tests were taken from the ulcer at the pre-debridement phase along with urine and perianal cultures. Baseline haematological parameters along with radiological evaluation of the local area were performed. Antibiotic treatment was started to prevent septicaemia, along with infusion of amino acids and fresh frozen plasma and packed red blood cells for 
Table 1 Comparison of pressure ulcer prevalence studies among different countries

\begin{tabular}{llll}
\hline Study & Country & $\begin{array}{l}\text { Number of } \\
\text { patients included }\end{array}$ & $\begin{array}{l}\text { Prevalence of } \\
\text { pressure ulcers }\end{array}$ \\
\hline Chauhan et al. [1] & India & 445 & $4.94 \%$ \\
Mehta et al. [2] & India & 358 & $7.8 \%$ \\
Kottner [3] & Germany & 3610 & $3.9 \%$ \\
Zhou [4] & China & 25,264 & $1.26 \%$ \\
Amir [5] & Indonesia & 1132 & $3.6 \%$ \\
\hline
\end{tabular}

Table 2 Overview of all the three cases in terms of different variables

\begin{tabular}{llll}
\hline Variable & Case 1 & Case 2 & Case 3 \\
\hline Age (years) & 45 & 22 & 30 \\
$\begin{array}{l}\text { Gender } \\
\text { Time since injury }\end{array}$ & M & M & M \\
(months) & & 4 & 4 \\
$\begin{array}{l}\text { Level of injury } \\
\text { AIS }\end{array}$ & T5 & T11-T12 & T8 \\
$\begin{array}{l}\text { Time to PrU occurrence } \\
\text { (days) }\end{array}$ & 20 & A & A \\
$\begin{array}{l}\text { Length of hospital stay } \\
\text { (days) }\end{array}$ & 175 & 45 & 38 \\
$\begin{array}{l}\text { Wound complications } \\
\text { Healing of PrU }\end{array}$ & Superficial wound & Nil & Nil \\
$\begin{array}{l}\text { Improvement in Hb } \\
\text { (gm/dl) }\end{array}$ & Excellent & Excellent & Excellent \\
$\begin{array}{l}\text { Improvement in serum } \\
\text { Protein (gm/dl) }\end{array}$ & 1.4 & 5.6 & 2.8 \\
\hline
\end{tabular}

improving the general condition of the patient [7]. Patients were placed on alternating air pressure mattresses. The operative stage was then divided into proximal femoral resection, thorough debridement, (Fig. 1a-d), and the TFL flap surgery.

\section{Case 1}

A 45 year old male, mechanical worker presented with AIS A paraplegia and neurogenic bladder and bowel with a stage 3 sacral PrU and a stage 4 right trochanteric PrU. The Patient had fallen from an unknown height 5 months earlier and had suffered fracture of the fifth thoracic vertebrae. The PrUs first appeared 20 days after injury and gradually worsened. Personal medical history was positive for tobacco use. Initial radical debridement of both sacral and trochanteric PrUs was performed with excision of necrotic and fibrous tissue and heterotrophic bone, in addition to proximal femoral resection. Debridement of the exposed cartilaginous surface of acetabulum was done and debrided tissue was sent for histopathological and microbiological examination. This procedure was followed by multiple successive debridements of the cavity. Two units of blood along with amino acids and fresh frozen plasma were transfused before the final flap surgery.

After the wounds were cleaned, the final surgical procedure for closure by TFL flap for the right trochanteric PrU, and a fasciocutaneous flap with split skin grafting (SSG) for the sacral PrU was planned. The Trochanteric PrU was operated on first, and four weeks later the sacral PrU was operated on. After anaesthesia, the patient was laid in a semilateral position, and the anterior margin of the flap was decided by making a line connecting the anterior superior illiac spine and the lateral tibial condyle. The posterior border of the flap was represented by the greater trochanter, the superior border by the iliac crest, and the inferior border within $8 \mathrm{~cm}$ from the joint line. Both the PrUs and the edges of the skin were debrided. The limb was slightly flexed at the hip and measurements of the tissue defect were done. Size and location of the flap were decided by following the principle of the planning in reverse. The lower border of the flap was incised first, followed by the anterior and posterior borders. The dissection was performed in a distal to proximal direction in the subfascial plane. The vascular pedicle was identified, located at the preoperatively anterior marked site (Eight to $10 \mathrm{~cm}$ distal to the anterior superior iliac spine). The flap was then transferred to the recipient site, and covered the tissue defect. The raw area created was closed primarily. A fasciocutaneous flap with SSG containing multiple epidermal nicks was done for the sacral PrU four weeks later (Fig. 2a-d). One unit of blood was required intraoperatively. The size of the flap was slightly larger than the defect. During the postoperative stage, care was taken to prevent hyperflexion of the hip through positioning with pillows. The operative site was kept free and turning to this side was not allowed until sutures were removed. Regular inspection of the flap was performed by the surgeon until suture removal 18 days postoperatively. The patient was hospitalized for 175 days for the management of these PrUs and the interval between final surgery and discharge was 58 days.

The patient was seen in follow-up for 14 months. The patient used an Indian made wooden bed with hand woven ropes (Charpai) and a cotton mattress at home (Fig. 3). There was a superficial gap of $3 \mathrm{~cm}$ at recipient site, which was treated with local wound care. The sacral and the trochanteric regions were free of PrUs with excellent uptake of the flap and the SSG at final follow-up. There was a rise in haemoglobin by $3.4 \mathrm{gm} / \mathrm{dl}$ and in serum protein by $1.4 \mathrm{gm} /$ $\mathrm{dl}$ after healing of the PrUs. 
Fig. 1 a Photo of patient (case 3) showing exposed proximal femoral region through trochanteric PrU. b Excision of proximal femoral region through trochanteric PrU. c Excised proximal femoral region. d Debridement of the resultant cavity after proximal femoral resection
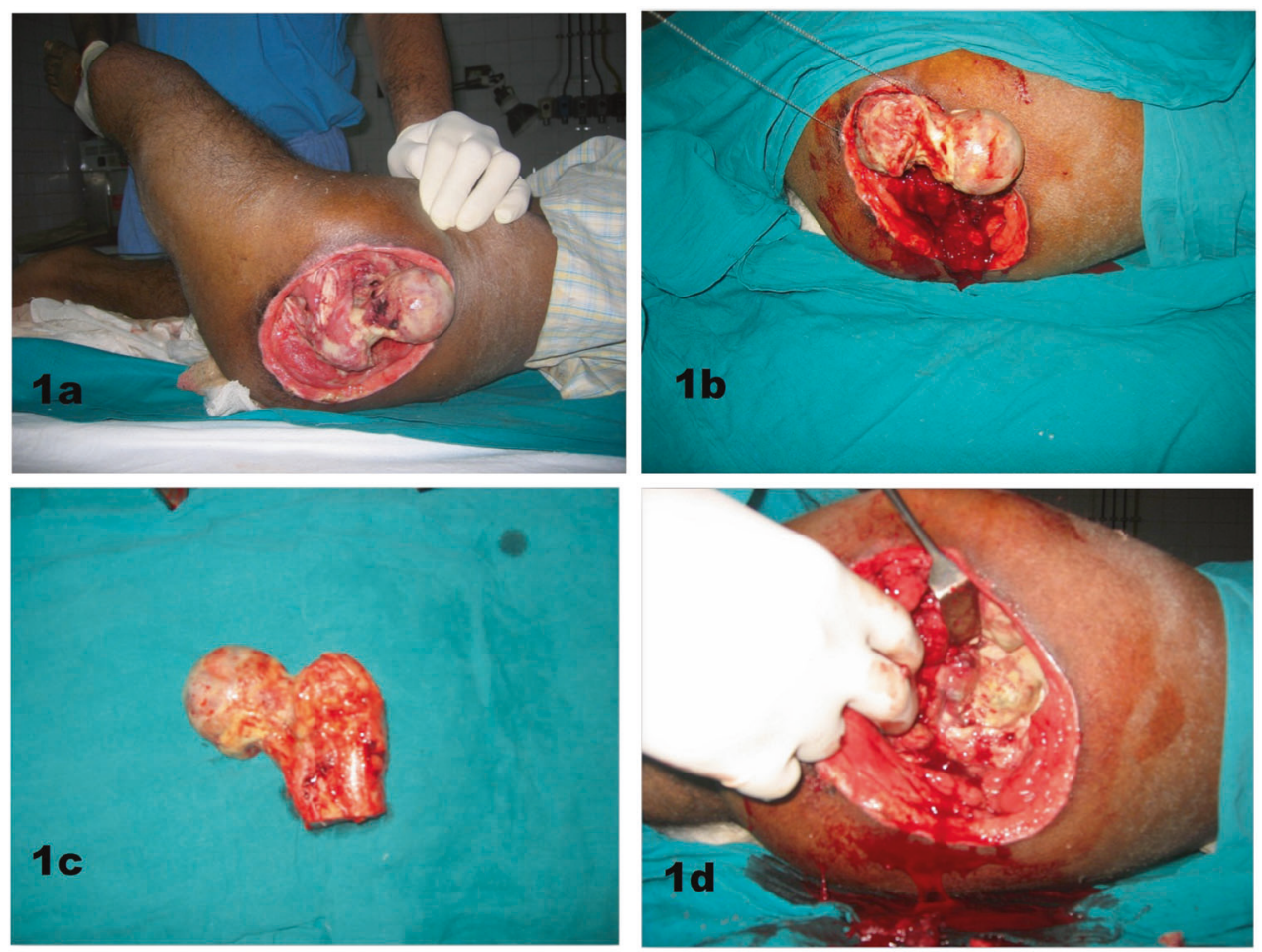

Fig. 2 a Photo of patient (case 1) showing sacral and trochanteric PrUs. Trochanteric PrU is communicating with the hip joint with exposed proximal femur. b Final intra operative photo showing transfer of the Tensor Fascia Lata Flap over trochanteric PrU along with primary closure of the donor site. c Photo of the operative area at final follow-up showing complete healing of flap area with no signs of recurrence. d Photo showing fasciocutaneous flap with SSG with multiple epidermal nicks was done for the sacral PrU
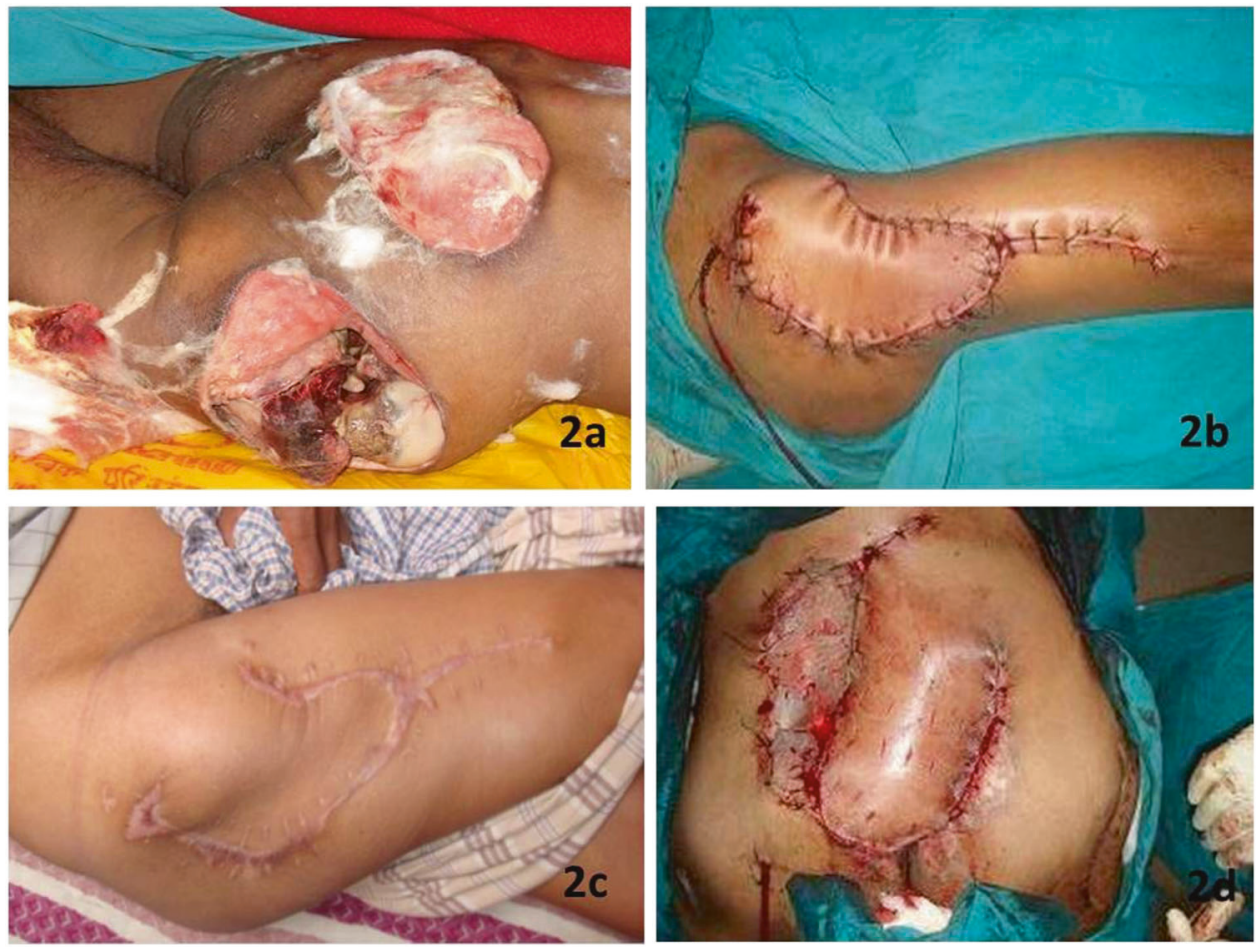

\section{Case 2}

A 22 year old male student presented with stage 4 sacral and bilateral trochanteric PrUs four months post fall from unknown height with T11 and T12 fractures. He had AIS A paraplegia with neurogenic bladder and bowel. According to the patient's history the PrUs appeared 45 days after the injury.

Initial radical debridement of both the sacral and the trochanteric PrUs was performed prior to performing proximal femoral resection of both sides in two separate surgical procedures. Two units of blood and fresh frozen 


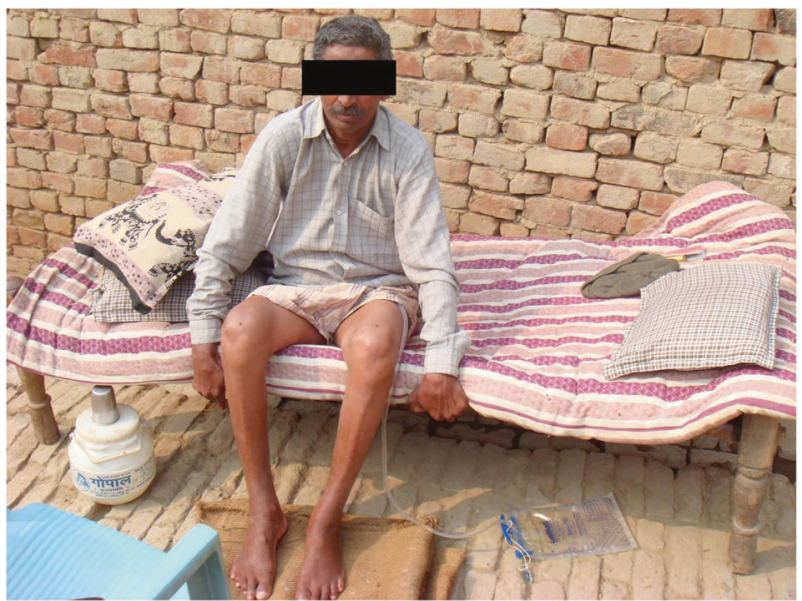

Fig. 3 Photo of the patient (case 1) showing use of Indian made wooden bed (Charpai) with cotton mattress and rehabilitation of patient at home

plasma were transfused in connection with these procedures. Histopathological and microbiological samples of the debrided tissue were taken.

After the wounds were cleaned, the final surgical procedure for closure by TFL and SSG was planned for the right trochanteric PrU and the sacral PrU. The TFL flap surgery for the right trochanteric PrU and the SSG for the sacral PrU were performed using the same method described in case one. The surgery for the left side trochanteric PrU by using a TFL flap was planned to be performed two weeks later. Primary closure was unable to be performed of the donor site because of the recipient area was too large. A SSG was performed at the donor site (Fig. 4a-d). General postoperative care was performed as in case one. Sutures were removed 14 days post-operatively for the right trochanteric and the sacral region whereas the left trochanteric sutures were removed 17 days post-operatively. Duration of hospitalisation was 115 days and the patient was discharged after 92 days the final flap surgery.

The patient used an alternating air pressure mattress at home. He remained in follow-up for 18 months. There were no wound related complications. Excellent healing was noted of both the trochanteric and the sacral regions. There was a rise in haemoglobin by $5.6 \mathrm{gm} / \mathrm{dl}$ and in serum protein by $0.9 \mathrm{gm} / \mathrm{dl}$ after healing of the PrUs.

\section{Case 3}

A 30 year old male labourer presented with stage 4 sacral and left trochanteric PrUs four months post fall from unknown height with T8 fracture. He had AIS A paraplegia with neurogenic bladder and bowel. The PrUs appeared 38 days after the injury. Personal medical history was positive for tobacco use.
A thorough debridement of the trochanteric PrU was performed along with resection of the proximal femoral region and debridement of the cavity and the exposed cartilaginous surface of the acetabulum. Two units of blood and fresh frozen plasma were transfused prior to this surgery. Precautions were taken as previously described, with use of an alternating air pressure mattress.

After multiple debridements the PrUs became healthy. TFL flap surgery was planned for the trochanteric PrU. A small area of the PrU was unable to be covered with the TFL flap, however, it was covered with a SSG (Fig. 5a-d) and a primary closure of the donor site was achieved. General postoperative care was performed as described in previous cases. Sutures were removed 18 days postoperatively. Hospitalisation lasted 92 days with a 38 days interval between the final flap surgery and discharge.

The patient used an alternating an air pressure mattress at home. The patient remained in the follow-up for 15 months. There were no postoperative wound related complications. Excellent healing was noted at the final follow-up. Haemoglobin increased by $2.8 \mathrm{gm} / \mathrm{dl}$ and serum protein level increased $0.9 \mathrm{gm} / \mathrm{dl}$ after healing of PrUs.

\section{Discussion}

PrUs are a common complication of patients with SCI, leading to increase in morbidity and financial burden to the family $[8,9]$. In India, care patterns are often different from that of developed nations. The majority of the Indian population is in rural areas and are at greater risk of SCI due to fall from height or fall of a heavy object hitting the persons related to lack of fencing to wells, roofs, and staircases, and also poorly built/substandard mud homes [10]. A lack of awareness regarding the severity of the situation leads to delayed presentation of the patient at hospital [10]. Difficulty in management of the PrUs increases with the increasing grade of the PrUs as they lead to necrosis and osteomyelitis of the underlying bone and joints. Ischial and trochanteric ulcers are very common, and are often difficult to manage because of involvement of the hip joint [11].

Neglected SCI patients with large PrUs are common in India [12-14]. Management of large PrUs with hip joint involvement is a challenge. The technique described in the current study is suitable in the management of such PrUs, effectively taking care of both the infection and the healing [14]. A femoral head resection followed by a muscle flap closure in persons with paraplegia was first described in literature by Mathes et al in 1980 [11]. Later, Girdlestone arthroplasty was described as a surgical method for getting free access to, and effective drainage of the hip joint [15]. In the management of recalcitrant PrUs with infection 
Fig. 4 a Photo of the patient (case 2) in prone position showing sacral PrU and left trochanteric PrU. b Photo of the same patient showing right trochanteric PrU. c

Intraoperative photo showing raw area with Tensor Fasia lata Flap during surgery over right trochanteric PrU. d Photo at final follow-up showing excellent uptake of flap and split skin graft
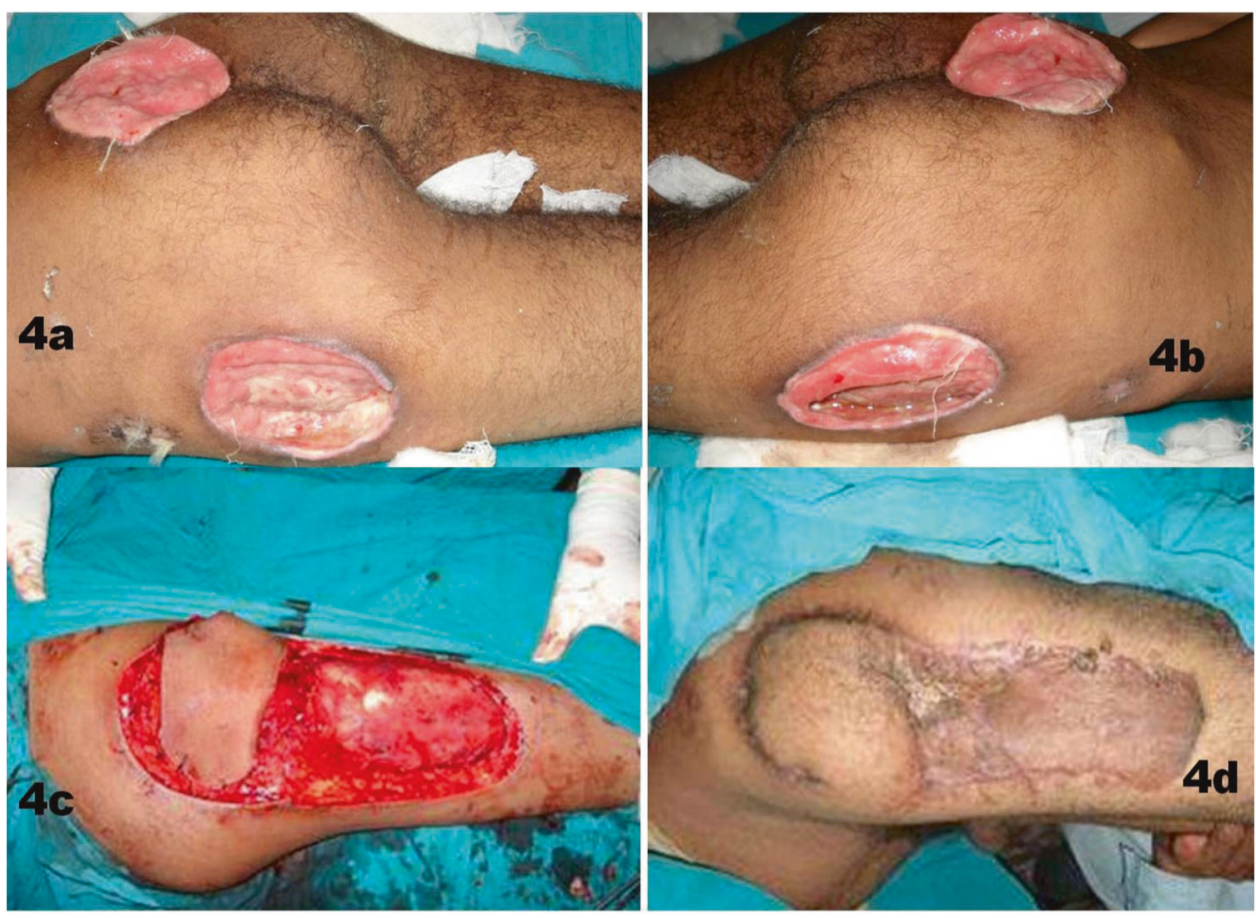

Fig. 5 a Photo of patient (case 3) showing trochanteric PrU communicating with the hip joint with exposed proximal femur. b Intraoperative photo showing TFL flap raised and transferred to the PrU. Donor site stitched prior to stitching of the flap at PrU site. c Final intra operative photo showing transfer of the Tensor Fascia Lata Flap over trochanteric PrU along with primary closure of the donor site. Small area of the PrU left uncovered by flap was skin grafted. d Photo of the operative area at final follow-up showing complete healing of flap area with no signs of recurrence
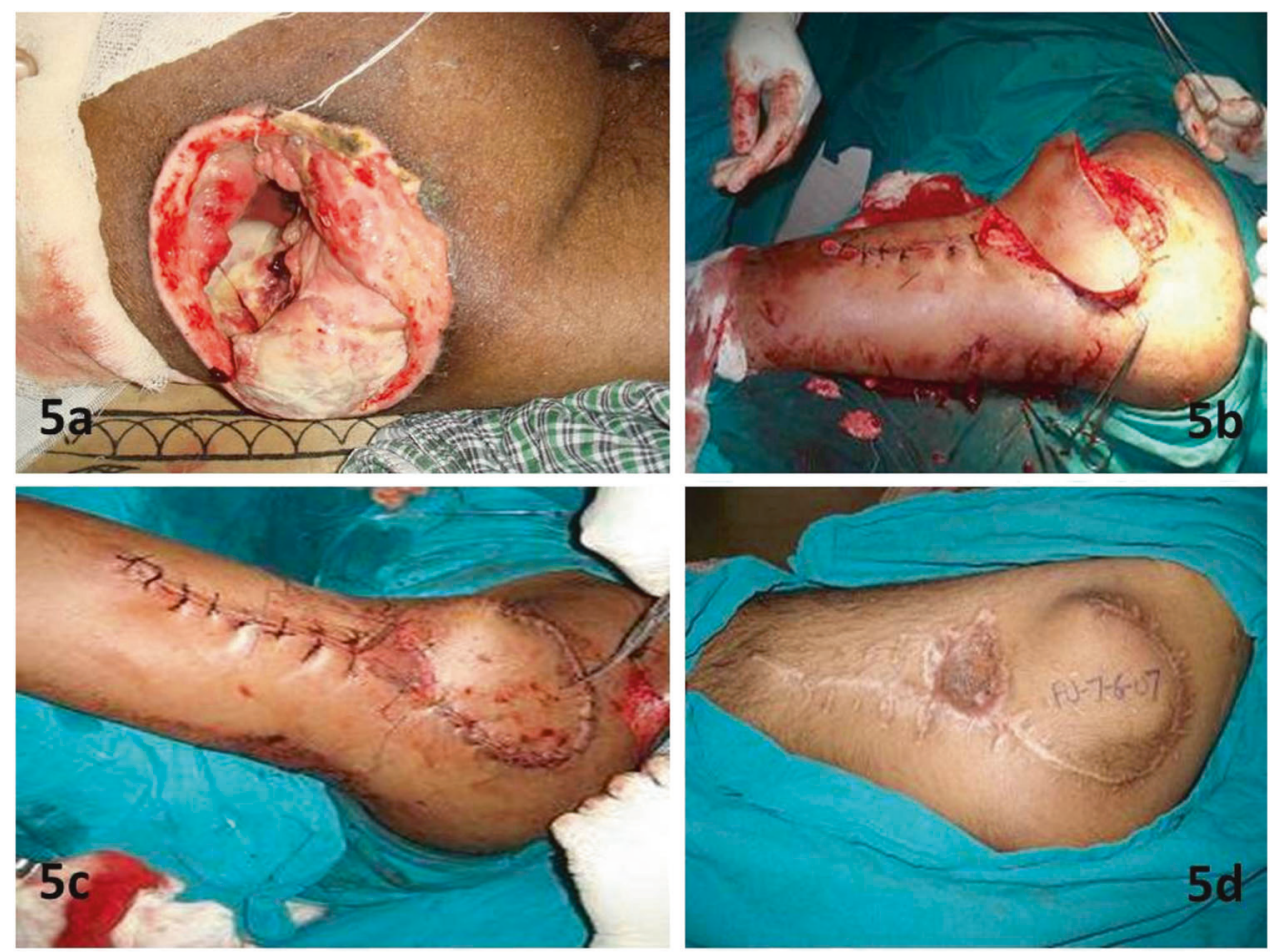

spreading to the hip joint, the use of a Girdlestone arthroplasty followed by coverage with muscle flaps plays a key role. The presence of an infected prosthesis (femoral stem arthroplasty/hemiarthroplasty) makes the situation even worse because of the combination of decreased vascularity, fibrosis, inflammation, extensive scarring, and heterotrophic calcification around the wound. Together with a malnourished and immobilised patient, it makes it difficult to treat PrUs properly [6].

Initial debridement is focused on creation of a large, solitary, unbarred cavity by proximal femoral resection which allows successful drainage and dressing of the affected deeper tissue. This also prevents persistence of secluded collections and abscess formation. The avascular exposed bone, excludes 
the possibility of any salvage procedure [12]. Klein et al. [16] used the vastus lateralis muscle flap with a skin graft following proximal femoral resection to treat ischial or trochanteric pressure sores communicating with the hip joint.

Debridement of the cavity was carried out until healthy tissue and bone was reached. Multiple successive debridements were needed to create a granulating surface over the wound for successful adherence of the TFL flap after the final surgery. Proper clinical examination is the most important way to confirm any hip joint involvement and proceeding for the proximal femoral resection. The overall health status of the patients improved before the final stage flap surgery through a high caloric protein diet along with transfusion of blood and fresh frozen plasma. The final closure was attempted after eradication of the infected, necrotic and fibrous tissue from the cavity.

Hill and Nahai et al. [17] first described the TFL flap as a free myocutaneous flap. This is a myofasciocutaneous flap that can be used as a pedicled flap for a wide variety of regions including the trochanter, groin, perineum, ischium, and lower abdominal areas, which might be affected following trauma, infection, orthopaedic intervention as well as PrUs and resection of malignant lesions and lymph node dissection [13, 14].

Other types of flaps have also been used in the management of trochanteric ulcers including anterolateral thigh flap, triple muscle flap, and Vastus lateralis muscle flap [6, 18-20]. Some studies $[6,14,21]$ have used proximal femoral resection along with pedicled flapping with a success rate of $85-100 \%$ for such PrUs, describing a modification in the TFL flap for these cases. In our study we used a combined TFL and vastus lateralis flap for packing the cavity by deepithelialising the distal margin of the TFL flap [11]. The TFL flap is a reliable flap having good vascularity and is composed of skin, subcutaneous tissue, fascia, and muscle. Because this muscle is expendable, it causes minimal donor site pathology, and no knee weakness [22]. The TFL flap allows using the same donor site, avoiding surgical incision. Its anatomy is more constant, perforators are always present, and its pedicle is sufficiently long with an average length of $8 \mathrm{~cm}$ [23].

Previous studies $[16,21]$ have described the use of methods such as external fixators and silastic cushions for prevention for pistoning of a flailing femur against the acetabulum and thus movement of the flap after the final stage flap surgery. Similarly, some studies $[6,24]$ describe the procedure without use of any stabilising devices, thus without adversely affecting their outcomes. Instead simple positioning to prevent hyperflexion as well as frequent position changes for prevention of these movements are recommended. In our study we obtained good results with simple positioning and frequent position changes.

Thus, this method of proximal femoral resection, wide excision and filling with a TFL muscle flap seems to be a good surgical option for trochanteric PrU coverage; leading to improvement in general health and quality of life.

In summary, severe PrUs are a common complication of complete SCI in developing countries like India and in turn, are a barrier for the rehabilitation process. Proximal femoral resection is an acceptable procedure for treating PrUs communicating with the hip joint. In addition, use of a pedicled TFL muscle flap is a versatile, reliable, anatomically constant and less time consuming procedure, with minimal donor site morbidity for the coverage of recalcitrant trochanteric PrUs.

Author contributions All authors contributed to the design, analysis, and writing of this manuscript.

\section{Compliance with ethical standards}

Conflict of interest The authors declare that they have no conflict of interest.

Statement of ethics All procedures performed in this study were in accordance with the ethical standards of institution, the governmental regulations and with the 1964 Helsinki declaration and its later amendments.

Publisher's note: Springer Nature remains neutral with regard to jurisdictional claims in published maps and institutional affiliations.

\section{References}

1. Chauhan VS, Goel S, Kumar P, Srivastava S, Shukla VK. The prevalence of pressure ulcers in hospitalized patients in a university hospital in India. J Wound Care. 2005;14:36-7.

2. Mehta C, George JV, Mehta Y, Wangmo N. Pressure ulcer and patient characteristics - a point prevalence study in a tertiary hospital of India based on the European pressure ulcer advisory panel minimum data set. J Tissue Viability. 2015;24:123-30.

3. Kottner J, Dassen T, Lahmann NA. Pressure ulcers in German nursing homes: frequencies, grades and origins. Z Gerontol Geriatr. 2011;44:318-22.

4. Zhou Q, Yu T, Liu Y, Shi R, Tian S, Yang C, et al. The prevalence and specific characteristics of hospitalised pressure ulcer patients: a multicentre cross-sectional study. J Clin Nurs. 2018;27:694-704.

5. Amir Y, Tan FE, Halfens R, Lohrmann C, Schols J. Pressure ulcer prevalence and care in Indonesian hospitals: a multicenter, Crosssectional evaluation using an extended Donabedian Model. Ostomy Wound Manag. 2017;63:8-23.

6. Acartürk TO. Treatment of large ischial ulcers communicating with the hip joint with proximal femoral resection and reconstruction with a combined vastus lateralis, vastus intermedius and rectus femoris musculocutaneous flap. J Plast Reconstr Aesthet Surg. 2009;62:1497-502.

7. Singh R, Singh R, Rohilla RK, Siwach R, Verma V, Kaur K. Surgery for pressure ulcers improves general health and quality of life in patients with spinal cord injury. J Spinal Cord Med. 2010;33:396-400.

8. Middleton JW, Lim K, Taylor L, Soden R, Rutkowski S. Patterns of morbidity and rehospitalisation following spinal cord injury. Spinal Cord. 2004;42:359-67. 
9. Rish BL, Dilustro JF, Salazar AM, Schwab KA, Brown HR. Spinal cord injury: a 25- year morbidity and mortality study. Mil Med. 1997;162:141-8.

10. Pandey V, Nigam V, Goyal TD, Chhabra H. Care of post-traumatic spinal cord injury patients in India: An analysis. Indian J Orthop. 2007;41:295-9.

11. Dinsdale SM. Decubitus ulcers: role of pressure and friction in causation. Arch Phys Med Rehabil. 1974;55:147.

12. Chhabra HS, Arora M. Neglected traumatic spinal cord injuries: causes, consequences and outcomes in an Indian setting. Spinal Cord. 2013;51:238-44.

13. Singh R, Rohilla RK, Siwach R, Dhankar SS, Magu NK, Sangwan SS. Health related problems and effect of specific interventions in spinal cord injury: an outcome study in Northern India. Eur J Phys Rehabil Med. 2010;46:47-53.

14. Singh R, Singh RB, Rohilla RK, Magu NK, Goel R, Kaur K. Improvisations in classic and modified techniques of flap surgery to improve the success rate for pressure ulcer healing in patients with spinal cord injury. Int Wound J. 2013;10:455-60.

15. Girdlestone GR. Acute pyogenic arthritis of the hip: an operation giving free access and effective drainage (Classic reprint). Clin Orthop. 1982;170:3-7.

16. Klein NE, Luster S, Green S, Moore T, Capen D. Closure of defects from pressure sores requiring proximal femoral resection. Ann Plast Surg. 1988;21:246-50.
17. Hill HL, Nahai F, Vasconez LO. The tensor fascia lata myocutaneous free flap. Plast Reconstr Surg. 1978;61:517-22.

18. Schmidt AB, Fromberg G, Ruidisch MH. Applications of the pedicled vastus lateralis flap for patients with complicated pressure sores. Spinal Cord. 1997;35:437-42.

19. Bovet JL, Nassif TM, Guimberteau JC, Baudet J. The vastus lateralis musculocutaneous flap in the repair of trochanteric pressure sores: technique and indication. Plast Reconstr Surg. 1982;69:830-4.

20. Mathes SJ, Alpert BS. Advances in muscle and musculocutaneous flaps. Clin Plast Surg. 1980;7:15-26.

21. Rubayi S, Pompan D, Garland D. Proximal femoral resection and myocutaneous flap for treatment of pressure ulcers in spinal injury patients. Ann Plast Surg. 1991;27:132-8.

22. Jones NF, Eadie P, Johnson PC, Mears DC. Treatment of chronic infected hip arthroplasty wounds by radical debridement and obliteration with pedicled and free muscle flaps. Plast Reconstr Surg. 1991;88:95-101.

23. Hubmer MG, Schwaiger N, Windisch G, Feigl G, Koch H, Haas FM, et al. The vascular anatomy of the tensor fasciae latae perforator flap. Plast Reconstr Surg. 2009;124:181-9.

24. Evans GR, Lewis VL, Mason PN, Loomis M, Vander Kolk CA. Hip joint communication with pressure sore: the refractory wound and the role of girdlestone arthroplasty. Plast Reconstr Surg. 1993;91:288-94. 